\title{
More or Less Integrated Ocean Management: Multiple Integrated Approaches and Two Norms
}

\author{
Lena Schøning \\ UIT The Arctic University of Norway
}

Received (SL): 29 January 2019; $\quad$ accepted: 1 February 2019

Address correspondence to: Lena Schøning, K.G. Jebsen Centre for the Law of the Sea, at UIT The Arctic University of Norway, . Email: lena.schoning@uit.no.

Financed by the K.G. Jebsen Foundation and UiT The Arctic University of Norway. The author would like to thank the anonymous reviewer and editor for highly appreciated feedback, and Ingvild Ulrikke Jakobsen, David Langlet, Vito de Lucia and Nigel Bankes for discussions and comments on earlier drafts. The responsibility for errors of fact or judgment remains with the author. 



\begin{abstract}
Through a normative lens, this article investigates integrated ocean management and the multiple concepts that it involves. Whereas international law provides legal authority to coastal states to manage their ocean area entitlements, no single legally binding norm specific to integrated ocean management exists. Nevertheless, by combining different internationally recognized sources, this article identifies and discusses two normative concepts applicable in coastal state integrated ocean management. These are: (1) the framing of integrated ocean management as a management process, and (2) the incorporation of environmental, economic and social concerns into an ocean management policy.
\end{abstract}

Keywords: Ocean governance, integrated ocean management, integrated approach, ecosystem approach, marine environmental protection, sustainable development 


\section{Introduction}

With the global human population growing and the demand for resources continually increasing, the ocean is on the international agenda for exploration and exploitation. ${ }^{1}$ As newspapers and social media publish pictures of whale stomachs filled with plastic bags and seahorses clinging to Q-tips, awareness of the deleterious effects of human activities on the marine environment is growing, and the need to protect the marine environment is gaining recognition. ${ }^{2}$

Integrated ocean management is one response to these challenges. Indeed, the 2017 UN Ocean Conference stressed the need for an integrated approach, at all levels, to reach ocean sustainability. ${ }^{3}$ More than 30 countries have arrangements that fall under the heading of “integrated ocean management”, and at least 66 are developing arrangements for this type of

management. ${ }^{4}$ In addition, regional initiatives for integrated coastal and ocean management also exist for the Mediterranean ${ }^{5}$, the North Sea ${ }^{6}$ and the Baltic Sea. ${ }^{7}$

Yet despite this widespread belief in and the ongoing use of integrated ocean management, no common definition of the concept exists, and it raises multiple questions: Is it one or more concepts, what does it require or suggest, what is its normative value, and what is the breath of issues that integrated ocean management attempts to resolve? This article addresses these questions.

The international legal literature discusses many aspects of integrated ocean governance and management. ${ }^{8}$ The variation of integrative concepts calls for strikingly different analyses. The difference depends on, for example, whether the object of the analysis is the integrated ocean management regime of one or more coastal states, the integrative aspects of an international convention or a regional initiative, or an integrative or holistic perspective detached from any object and more conveniently used as an umbrella term. ${ }^{9}$ Accordingly, multiple 
concepts of integrated ocean management exist, each taking its own analytical approach, with varying premises and content. ${ }^{10}$ This reality necessitates a clarification of the premises and scope of the integrative concepts investigated in this article, which will be provided after the identification of the responsible actors and their legal powers. ${ }^{11}$

As currently defined under international law, the central right and obligation to manage the ocean - as far as territorial waters, the exclusive economic zone (EEZ) and the continental shelf are concerned - weigh upon individual coastal states. ${ }^{12}$ Thus, coastal states are the designated responsible actors charged with managing their ocean area entitlements. ${ }^{13}$ But, does international law require of them to manage their ocean areas taking an integrated approach? One could argue that the international obligation to protect the marine environment presumes such an integrated approach. However, as multiple ways of protecting the marine environment exist, as well as multiple integrative concepts (including those combining marine environmental protection with other objectives), the article rules out that international law dictates a specific norm of integrated ocean management. ${ }^{14}$ Yet, integrative concepts exist in both international conventions and decisions related thereto, in regional agreements, and in international policy statements that are widely recognized by governments worldwide. Combining these internationally recognized sources enables the identification and discussion of two integrative concepts. While their normative value is not that of binding legal obligations, they may be capable of generating formal norms, of capturing a shared understanding, and of providing guiding standards by which to conform. Consequently, the article explores norms beyond formal legally binding norms.

Accordingly, this article explores those integrative concepts applicable to ocean management that have normative value, e.g. by being manifest in internationally recognized 
sources. More specifically, the investigation focuses on integrative concepts relevant for ocean management that use the term "integrate". Moreover, the article takes the perspective of the coastal State, as opposed to that of an international or regional institution or a sub-national governmental entity. The article chooses this perspective partly to focus on the designated responsible actors charged with managing ocean area entitlements, and partly as it opens the opportunity to investigate distinct national IOM regimes and the norms applicable thereto. Furthermore, fundamental differences exist between the legal authority of a coastal State compared to the more limited scope available through delegation, whether to sub-national government entities or regional bodies. Moreover, integrative concepts are widely used by coastal states. ${ }^{15}$

Thus, the article brings content to integrated ocean management by identifying and discussing two integrative concepts applicable to coastal State’s integrated ocean management: (1) To develop or maintain an integrated ocean management process, and (2) to integrate environmental, economic and social concerns into an ocean management policy. The two concepts differ in content, as the first one frames IOM as a management process and the second one concerns the incorporation of certain concerns into any policy, not just an integrated ocean management policy. The two concepts highlighted illustrate how integrative concepts relevant for ocean management differ.

The article is divided into five sections. Following this introduction, section II briefly considers the scope of coastal State integrated ocean management, including the patchwork of distinct nationally devised regimes. Then, in section III, the article investigates the content and normative value of the integrated ocean management process, before discussing in section IV the 
content and normative value of integrating environmental, economic, and social considerations into (integrated ocean management) policies. Finally, the article offers some concluding remarks.

\section{The Scope of Integrated Ocean Management}

At the international level, the Law of the Sea confers power upon the coastal state while also limiting these powers. ${ }^{16}$ The United Nations Convention on the Law of the Sea ${ }^{17}$ (UNCLOS) delimits the ocean space under coastal state jurisdiction, and the ocean area entitlements of a coastal state in its territorial sea, contiguous zone, EEZ, and continental shelf. The sovereignty of the coastal states extends to its territorial sea, although subject to UNCLOS and other rules of international law. ${ }^{18}$ In its EEZ, the coastal state has sovereign rights to explore, exploit, conserve and manage natural resources, subject to the freedom of navigation or other internationally lawful uses of the sea by other states. ${ }^{19}$ The coastal state exercises over the continental shelf sovereign rights for the purpose of exploring and exploiting its natural resources. ${ }^{20}$ These legal rules define the scope, or the limits within which costal states may take action at sea, and set some of the parameters of ocean management. However, these legal rules do not define the scope of authority to address activities and pressures on shore affecting the ocean. This authority is generally limited to the territory and the citizens under the sovereignty of the state.

The ocean area entitlements and territorial rights provided at the international level constitute the legal authority available to the coastal state. However, through an internal distribution of power, the coastal state's authority is divided between sectoral and sub-national units. Thus, the scope of the IOM of an individual coastal state will naturally vary according to the authority delegated for ocean management, as well as practical, financial, political, institutional, and normative constraints on management. These premises may be more or less 
explicitly identified in a state's IOM policy. The division of authority can be due to sector interests or political positions, as well as historical, constitutional, institutional, or other reasons, such as a natural science focus on the symptoms affecting the marine environment, as opposed to a social science focus on human impacts on the ocean. These path dependencies ${ }^{21}$ in turn impact the ocean management arrangements in terms of the resources, competence and knowledge available, and necessarily, the focus and strategies for ocean management.

These national level self-inflicted restrictions together with international restrictions and obligations create general limitations on the scope of IOM. As such, the capacity of IOM to yield desired outcomes is correspondingly limited. Consequently, this article suggests that the scope of IOM should be clearly and transparently defined by the coastal state. Having considered these limitations, the next section discusses two general international concepts of IOM, providing potential for integration.

\section{The Integrated Ocean Management Process}

\section{The Scope and the Sources}

This section explores the content and normative value of the IOM concept existing in those international instruments with broad governmental support that use terms similar to "integrated ocean management.” Thus, sources that refer to concepts similar to IOM but that use different terms and expressions - such as ecosystem approach, marine spatial planning or ocean governance - are not investigated. This article deems all these concepts "holistic concepts", as they each from their own angle(s) promote a comprehensive approach to the management of ecosystems, the planning of marine spaces, or the management of the ocean. ${ }^{22}$ Although these other holistic concepts are related to and relevant for IOM, it is outside the scope of this article to investigate them in depth, even if their exclusion may potentially weaken the conclusions. 
Nevertheless, the investigation reveals that certain IOM sources refer to the ecosystem approach, and therefore the ecosystem approach will peripherally be considered.

Four variations of the concept of integrated ocean management will be briefly discussed: "integrated management and sustainable development of coastal and marine areas" (IMCM), “integrated coastal and zone management” (ICZM), “integrated marine and coastal area management” (IMCAM), and “integrated coastal management” (ICM). The purpose is to identify, if possible, common content or scope of a potential norm.

IMCM stems from Agenda 21, a plan of action adopted alongside the Rio Declaration on Sustainable Development in 1992, and later reiterated in multiple international documents promoting sustainable development. ${ }^{23}$ No definition of IMCM exists; the term is merely used in a subheading of Chapter 17 of Agenda 21, on the protection of the oceans. The chapter refers to an "integrated policy and decision-making process", and identifies the precautionary approach and stakeholder involvement as objectives. Moreover, it encourages the development of national coordinating mechanisms including integrated management plans and environmental impacts assessments. $^{24}$

ICZM is a concept introduced by the ICZM Protocol to the Barcelona Convention for the Protection of the Marine Environment and the Coastal Region of the Mediterranean. ${ }^{25}$ Article 2 (f) defines ICZM as

a dynamic process for the sustainable management and use of coastal zones, taking into account at the same time the fragility of coastal ecosystems and landscapes, the diversity of activities and uses, their interactions, the maritime orientation of certain activities and uses and their impact on both the marine and land parts. ${ }^{26}$

Article 18(1) of the ICZM Protocol provides that "[e]ach Party shall further strengthen or formulate a national strategy for integrated coastal zone management and coastal implementation 
plans and programmes". This formulation, in combination with the definition of "integrated coastal zone management” as a "dynamic process (...)”, essentially imposes upon coastal states the obligation to develop or maintain integrated ocean management processes. Article 18.2 further details the process, stating that it should provide "an analysis of the existing situation" and "set objectives, determine priorities (...), enumerate the measures (...), and set an implementation schedule”. The ICZM Protocol further includes objectives and principles of ICZM, and regulates specific "elements" of ICZM, including the protection and sustainable use of the coastal zone, through the establishment of construction-free coastal zones and the necessity of ensuring that the impacts of economic activities are balanced with environmental concerns. The ICZM concept is also at the heart of the Indian Ocean Commission, which works with national level ICZM implementation. The Indian Ocean Commission refers to ICZM as a management principle. ${ }^{27}$

IMCAM is a concept of the CBD, enshrined in decisions made by the CBD's governing body, the Conference of Parties (COP), ${ }^{28}$ in its implementation strategies ${ }^{29}$ and technical reports. ${ }^{30}$ In these documents, IMCAM is generally referred to as an implementation tool, for the implementation of the CBD with respect to the conservation and sustainable use of marine and coastal biodiversity, the ecosystem approach or biodiversity targets and strategies. ${ }^{31}$ IMCAM is also relevant at the national level, including “(w)here appropriate, [in] developing and adopting a national integrated marine and coastal area management strategy" ${ }^{32}$ Moreover, the CBD national reporting questionnaire requests information about its national implementation. ${ }^{33}$ Definitions of IMCAM include the following one from a technical report of 2004:

a participatory process for decision making to prevent, control, or mitigate adverse impacts from human activities in the marine and coastal environment, and to contribute to the restoration of degraded coastal areas. ${ }^{34}$ 
Another CBD technical report of 2005 provides this definition:

a continuous, dynamic, iterative, adaptive and participatory process in which a coordinated strategy is developed and implemented to allow sustainable resource use. ${ }^{35}$

The CBD COP decisions on IMCAM concern arrangements for and implementation of IMCAM. ${ }^{36}$ The technical reports and implementation strategies providing these definitions also include more elaborate descriptions of the concept. ${ }^{37}$ Together, these definitions, and the more detailed technical descriptions describe the IMCAM policy cycle, which includes a planning, implementation and evaluation phase as part of a larger process of participation and development. ${ }^{38}$ IMCAM is a flexible concept, typically to be applied as appropriate and relevant. The purpose of IMCAM is to achieve sustainable resource use and the protection of the environment. ${ }^{39}$ The ecosystem approach is frequently referred to in IMCAM descriptions, which therefore involves another holistic concept. Certain technical reports on IMCAM expand its application area to address management of land-based as well as ocean-based activities. For example, CBD technical experts have stressed that climate-change related aspects should be included in IMCAM programs,${ }^{40}$ and the need for effective strategies for waste reduction and management to reduce land-based pollution. ${ }^{41}$ A 2015 CBD technical report uses IMCAM interchangeably with ICM, which is analyzed next. ${ }^{42}$

ICM is a concept used by PEMSEA, the Partnerships in Environmental Management for the Seas of East Asia, a regional coordinating mechanism for the implementation of the Sustainable Development Strategy for the Seas of East Asia. ${ }^{43}$ The ICM framework covers key areas like policy, strategies and action plans; institutional arrangements; legislation; information and public awareness; financing mechanisms; and capacity development. ${ }^{44}$ The aim is sustainable development, another holistic concept. PEMSEA has developed an ICM code encapsulating "decades of ICM practices and experiences, particularly in the East Asian 
region.” 45 The code provides a thorough, well-structured presentation of ICM. The code is designed to aid local governments in their coastal development. ICM is defined by the ICM code as:

A dynamic, multidisciplinary and iterative process to promote sustainable development and management of coastal areas. It covers a full cycle of information collection, planning, decision making, management and monitoring of implementation. ICM uses the informed participation and cooperation of all concerned stakeholders to assess the societal goals in a given coastal area, and to take actions towards meeting these objectives. ICM seeks, over the long-term, to balance environmental, economic, social, cultural and recreational objectives, all within the limits set by natural dynamics (...). ${ }^{46}$

The structure of the code reflects a management process, providing recommendations on integrating planning, implementation, performance assessment, improvement and review. ${ }^{47}$ The ecosystem approach is included as an objective of ICM. As with IMCAM, ICM involves broad public management processes for reaching overall goals.

\section{Identifying the Norm}

Although these four concepts differ in content and form, they share many similarities, including their focus area, the processes they capture, their promotion of the ecosystem approach and the sources in which they are enshrined. ${ }^{48}$ The four concepts all focus, unsurprisingly, on the ocean, and on promoting coordination and cooperation, which equate to one form of integration. ${ }^{49}$

Moreover, using different expressions, each of them promotes the protection and

sustainable use of the marine environment: preserve, protect and sustainably use the coastal zone (ICZM), 50 "sustainable development” (IMCM and ICM), ${ }^{51}$ and sustainable resource use and protection of the environment (IMCAM). ${ }^{52}$ This shared focus on the protection of the environment raises an important point. Although UNCLOS imposes upon states "the obligation to protect and preserve the marine environment," 53 the potential to actually protect and preserve the marine environment through IOM is limited. Many of the main negative pressures on the 
marine environment are transported long-range by air, by rivers, by land runoff directly to the sea, by dumping from land or vessels, and are then further transported by ocean currents. The scope of IOM likely does not include the authority to prevent, reduce or prohibit these negative pressures. Therefore, pursuing marine environmental protection, as such, might more efficiently be done by climate change policies, waste management plans or policies addressing unsustainable consumption patterns. Nevertheless, dealing with negative pressures within the scope of an IOM policy for the purpose of marine environmental protection and sustainable use makes sense, but there needs to be an acknowledgment that IOM cannot on its own achieve such goals.

The next commonality of three of the concepts (ICZM, ICM and IMCAM) is their reliance upon the ecosystem approach. The ecosystem approach is referred to in different ways, sometimes as a foundation, sometimes as an objective. IMCM, which emerged in 1992, prior to the development of the ecosystem approach, does not refer to it. ${ }^{54}$ Aspects of the ecosystem approach are already captured by the promotion of the protection and sustainable use of the marine environment. Although the ecosystem approach is definitely relevant to integrated ocean management, the ecosystem approach is variously defined and interpreted. The complexity of the ecosystem approach makes it hard to determine its precise relationship to IOM, beyond an obvious and general connection..$^{55}$

The final, and arguably most prominent commonality of the four concepts is that they all integrate management processes. All the cited definitions refer to processes that are essentially management processes: IMCM to an "integrated policy and decision-making process," IMCAM to "a participatory process" and "a continuous, dynamic, iterative, adaptive and participatory 
process,” ICM to “(a) dynamic, multidisciplinary and iterative process," and the ICZM to "a dynamic process." 56

In light of these essential commonalities, this article argues for a common understanding of IOM, promoting coastal states to develop or maintain IOM processes for the protection and sustainable use of the marine environment, relying on the ecosystem approach. Details on how these management processes should be designed, maintained and improved vary in the sources promoting IMCM, IMCAM, ICM and ICZM, as evidenced by the cited definitions and more technical descriptions. A simplified synthesis of the management process would focus on stakeholder involvement and include the following phases: knowledge-gathering and analyses; policy and decision-making with regards to goals and priorities; tools and strategies; implementation and monitoring; evaluation and adaptation. ${ }^{57}$ Furthermore, the management processes linked to these concepts are generic management processes, in the sense that the processes are no different if the matter is terrestrial, in contrast to marine, or if the formal authority is a company or organization in contrast to a public entity. ${ }^{58}$

The sources of the four concepts are similar, yet different in form. As a protocol to a binding treaty, only ICZM is a source of internationally binding legal norms. ${ }^{59}$ Indeed, this article does not contend that a norm of customary law, based on the four concepts, exists in the absence of "other contextual and sociological conditions". ${ }^{60}$ Rather, inspired by the legality criteria defined by Brunnée and Toope, the article considers the normative value beyond that of a formal legal norm. ${ }^{61}$ Thus, the article will refer to a concept as a "norm" provided it presents some normative characteristics, including broad support and endorsement, consistency over time, public availability, and congruence between a concept and official action. ${ }^{62}$ 
The sources of IMCM, IMCAM, ICZM and ICM are similar in that they are all international instruments with broad governmental support. Taken together, they broadly express a shared understanding of IOM. Agenda 21 (IMCM) was adopted by 178 governments. The CBD (IMCAM) has 197 state parties; only four states are non-parties of which three are landlocked, and the forth one proclaims itself as the global leader on integrated management of the ocean. ${ }^{63}$ PEMSEA (ICM) has 11 Asian countries as partners. ${ }^{64}$ Ten Mediterranean countries and the EU have ratified the ICZM Protocol. ${ }^{65}$ All the sources are publicly available. IMCM was adopted back in 1992 and thus the concept has existed for decades. According to publicly available documents on national reporting to the CBD on IMCAM, 100 states have already implemented IMCAM at various stages, showing broad congruence between the concept and official action. ${ }^{66}$ Unlike a mere theoretical concept, the sources reflect a broad understanding and congruent pattern of action, with a clear influence on the conduct of states. These normative characteristics arguably bolster the existence of a norm of an IOM process. ${ }^{67}$ As the sources of the norm are not all legally binding, the article does not deem it a legally binding norm. ${ }^{68}$ It is nevertheless an internationally recognized norm.

To conclude, this section has identified an internationally recognized norm recommending coastal states to develop or maintain IOM processes, for the protection and sustainable use of the marine environment relying upon the ecosystem approach. ${ }^{69}$

The critical question remains whether IOM recommends a specific outcome or merely supports a process. The broad inclusion of stakeholders in that process will certainly not make prioritization easier. In any event, the process will provide a framework upon which to build an IOM policy, with a hopefully clear and transparent scope. 
The reader might wonder why article 6(b) of the Convention on Biological Diversity (CBD) has not yet been included as a source, as it includes the term "integrate”. As the discussion in the next section will reveal, the Convention text takes a different angle to integration. It does not promote integrated ocean management as such; rather, it promotes integrating specific concerns in any policies, including IOM policies.

\section{Integrating Specific Considerations}

\section{The Scope and the Sources}

Having identified the norm promoting the establishment of an IOM process, this section investigates another concept of integration that contributes to that process. The norm to be investigated is the international norm mandating the integration of specific considerations, of relevance to IOM and other policies.

The discussion below focuses on the foundation of the concept in internationally recognized sources, through such phrases as "integrate" in combination with "concerns" or "considerations". The following section will then discuss the substantive content of the concept, first, as evident from the sources on the sustainable development principle, and then as it emerges from the CBD treaty text and COP decisions. The final section links those findings to a common concept and discusses its normative quality.

The sources on the sustainable development principle comprise the documents and instruments on sustainable development adopted under the auspices of the UN (SD Documents). Chronologically speaking, the first were the Rio Declaration and the Agenda 21, adopted by 178 governments at the UN Conference on Environment and Development in $1992 .{ }^{70}$ Subsequent UN conferences and summits have adopted new formulations and have developed the concept of sustainable development in an extensive number of documents, statements, action plans and 
goals, while reaffirming previous efforts. ${ }^{71}$ The main objective of all these SD Documents is sustainable development, but a number of other connected goals, targets, approaches and concepts are also expressed, including the concept of integrating specific considerations.

The Rio Declaration and the Agenda 21 were adopted together, the Rio Declaration as a set of principles and the Agenda 21 as an action plan. Principle 4 of the Rio Declaration sets out that "[i]n order to achieve sustainable development, environmental protection shall constitute an integral part of the development process and cannot be considered in isolation from it.” The principle recognizes that development considerations and environmental protection cannot be seen as separate issues. This is further bolstered by case law, including in the Iron Rhine and Gabčíkovo-Nagymaros decisions. ${ }^{72}$ Chapter 8 of the Agenda 21 is more specific in how this principle may be implemented, as it promotes integrating environmental and development factors at the policy, planning and management levels, irrespective of a marine or terrestrial setting. The overall objective of chapter 8 is "to improve or restructure the decision-making process so that consideration of socio-economic and environmental issues is fully integrated (...)”. For this purpose, chapter 8 proposes (amongst others) to integrate environmental and development issues in economic, sectoral and environmental policies, strategies and plans. ${ }^{73}$ To improve decisionmaking processes, chapter 8 further promotes taking into account integrated economic, social and environmental considerations in decision-making "at all levels" and "in all ministries." ${ }^{74}$ For the purpose of this discussion, "social and economic" and "socio-economic and development" are understood to be essentially referring to the same issues. Taken together, these citations show that the Rio Declaration and Agenda 21 support a concept of integration understood as integrating social, economic and environmental considerations. The integration of environmental and socio-economic considerations is expressed conjointly and "cannot be seen in isolation.”75 
The overall principle of sustainable development supports this interpretation since it captures the three dimensions of development (social, economic and environmental), as expressed for instance by the UN General Assembly in 2012:

We therefore acknowledge the need to further mainstream sustainable development at all levels, integrating economic, social and environmental aspects and recognizing their interlinkages, so as to achieve sustainable development in all its dimensions. ${ }^{76}$

Thus, these sources relating to the principle of sustainable development support a concept of integrating social, economic and environmental considerations. As the integration of these considerations should be done at all levels and in all ministries, integration at the national level is also expected, such as in an IOM plan, policy or program.

The next sources to be investigated are the CBD treaty text and COP decisions. The question is to what extent the integration concept of the CBD involves integrating environmental, economic and social considerations. Article 6 of the CBD provides:

Each Contracting Party shall, in accordance with its particular conditions and capabilities:

(a) Develop national strategies, plans or programmes for the conservation and sustainable use of biological diversity or adapt for this purpose existing strategies (...); and

(b) Integrate, as far as possible and as appropriate, the conservation and sustainable use of biological diversity into relevant sectoral or cross-sectoral plans, programmes and policies.

Article 6(a) refers to national biodiversity strategies or action plans to be implemented by state parties. Article 6(b) emphasizes that "the conservation and sustainable use of biological diversity” shall be integrated into plans, programs and policies. For the purpose of the investigation, integrating "the conservation and sustainable use of biological diversity" is understood as covering the integration of environmental considerations. ${ }^{77}$

It is less obvious whether article 6(b) covers the integration of economic and social considerations. The phrase "sustainable use," may be understood as referring to use for economic 
purposes. Article 1 listing the objectives of the CBD uses the same phrase. ${ }^{78}$ The preamble to the Convention refers to, among other considerations, the economic value of biological diversity and its components, and the importance of economic development. Moreover, article 10(a) includes a provision similar to article 6(b), requiring parties to "integrate consideration of the conservation and sustainable use of components of biological resources into national decision-making," where the use of the term "resources" indicates economic use. Therefore, this section concludes that economic considerations must also be integrated into relevant sectoral or cross-sectoral plans, programs and policies.

The next question is the extent to which the integration concept in article 6 and 10(a) of the CBD mandates integrating social considerations. The ordinary meaning of "conservation and sustainable use of biological” diversity or resources does not explicitly cover social issues relevant for a single species (humans). Nonetheless, the preamble to the CBD broadly encompasses social values and social development. The listed objectives of the CBD however appear to give limited scope to social issues. The phrase "fair and equitable sharing of the benefits arising out of the utilization of genetic resources (...)”, limits the resources to be shared to genetic ones. Regardless, neither article 6(b) nor article 10(a) reiterate this limited "social" phrase found in the Convention's objectives, unlike the first two considerations (environmental and economic). Nevertheless, as will be shown, CBD COP decisions, in developing the ecosystem approach, have expanded on the Convention’s objectives to include a “social” aspect that goes beyond the treaty text. The ecosystem approach embraces a broad range of objectives including social ones. It is thus argued that the development of the ecosystem approach has led to a broadening of the concept requiring the integration of specific considerations. In support, 
reference can be made to a CBD COP decision of 2004, bearing the title "Further guidance on the implementation of the ecosystem approach principles”:

The approach incorporates three important considerations: (a) Management of living components is considered alongside economic and social considerations at the ecosystem level of organisation, not simply a focus on managing species and habitats. ${ }^{79}$

In a subsequent decision in 2009, under the heading "Meeting the three objectives of the Convention," the CBD parties emphasized "the integration of the three objectives of the Convention into relevant sectoral or cross-sectoral plans, programmes and policies." ${ }^{80}$ However, the CBD COP decisions do not systematically include all three considerations but rather refer to the need to integrate such considerations more indirectly. ${ }^{81}$ However, in decisions specifically addressing this norm, as in the citations above, all three objectives are specifically included. Furthermore, the interpretation according to which the relevant articles of the Convention include all three kinds of considerations is in harmony with the objectives of the CBD as expressed in its preamble. Arguably, social considerations are thus also covered by the integration concept of the CBD.

In line with SD Documents, CBD sources also adhere to the concept recommending the integration of environmental, economic and social considerations. Under the CBD umbrella, the concept has evolved since the convention text was adopted. The Conference of the Parties has contributed to the development of the integration concept as promoted by the sustainable development principle and its three pillars.

\section{Identifying the Norm}

Having established the three kinds of considerations to be integrated, this paragraph briefly discusses the sphere of application of the concept and its legal nature. 
The sources of the principle of sustainable development broadly address where such considerations should be integrated, referring to "decision-making” - as with article 10 (a) of the CBD - or "at all levels", which in both events cover an IOM policy. According to both article 6(b) of the CBD and the CBD COP decisions identified above, the considerations are to integrated into, amongst others, relevant cross-sectoral plans, programs and policies, which also cover an IOM policy.

Turning to the legal nature of the concept, the question is whether CBD COP decisions, which seek to expand the scope of the original Convention text to better align it with sources promoting the sustainable development principle, may result in any norm at all. ${ }^{82}$ Certainly, no legally binding norm can thus be created. The CBD COP decisions in question provide, as stated therein, recommendations rather than imposing requirements. Even the treaty text itself can hardly be seen as imposing clear obligations of a binding nature, since articles of the Convention, like article 6, rely on language like "in accordance with its particular conditions and capabilities" or “as far as possible and as appropriate” or "relevant (...) cross-sectoral plans (...).” Although these qualifying phrases in theory allow for the non-application of the norm (whether in whole or in part, as a result of it being found not to be relevant, possible or appropriate or in accordance with particular conditions or capabilities), it is hard to imagine that high-level environmental, economic and social concerns would be found not to be relevant, possible etc. in the context of an existing IOM policy.

Whereas the actual sources of this integrative concept vary - from treaty text to treatylike instruments, from goal-oriented policy documents to decisions providing guidance and recommendations for implementation - they all broadly express the development of a shared understanding of the concept. ${ }^{83}$ Beyond revealing a common understanding, the sources of the 
integrative concept in all their various forms, much like the sources of the IOM process, also call for a brief study of their normative characteristics. Those normative characteristics include the extent of support and endorsement, consistency over time, public availability, and congruence between the concept and official action. ${ }^{84}$ Although these criteria do not match those of a formal legal norm, they may sufficiently bolster the authority of the concept to justify characterizing it as a norm.

The sources considered all share worldwide international governmental support and endorsement. ${ }^{85}$ In the sources on the principle of sustainable development, the concept has been evident since 1992, showing some consistency over time. Although the sources are publicly available, the concept is not easily identified in the vast number of available documents emanating from the CBD and in those promoting the principle of sustainable development. The author is unaware of any data analyzing the potential congruence between the concept and specific state actions. Nevertheless, the wide endorsement of the concept and the consistency in approach arguably support the existence of a norm. Yet, the varying nature of the sources signifies that the norm, promoting the integration of all three kinds of considerations, cannot be deemed a legally binding norm. ${ }^{86}$ However, the concept as more narrowly defined in the CBD text (integrating environmental considerations) does qualify as a legally binding norm.

To conclude, an internationally recognized norm recommending the integration of environmental, economic and social considerations is applicable to IOM policies. ${ }^{87}$

The foregoing conclusion calls for a brief discussion of how the two norms relate to each other. The norm dictating the creation of an IOM process points to a management process, a simplified account of which includes stakeholder involvement, and these phases: knowledgegathering and analyses; policy and decision-making with regards to goals and priorities, tools 
and strategies; implementation and monitoring; and evaluation and adaptation. The norm of integrating considerations will have an effect at the outset on the knowledge-gathering-andanalysis phase, but may not have an impact on subsequent process steps. Depending on how the considerations are described and presented, integrating them may also result in clarification and transparency with regard to what has (or has not) been prioritized. The integration of these considerations may in turn lead to different priorities than if they had not been integrated. However, integrating considerations conceptually does not inevitably influence priorities, as taking something into consideration does not impose a duty to prioritize that consideration. The norm may therefore not improve the outcome of a decision, on behalf of the environment or with regard to economic or social considerations. Unless the consideration at hand involves other legal norms, such as the precautionary principle, it will up to the decision-makers of the IOM policy to determine if and to what extent priorities change as a result of the integration of the specific consideration. This could be seen as a shortcoming of the norm. ${ }^{88}$ The norm on integrating considerations, by not establishing priorities, yields no predictable outcome.

Another criticism that can be leveled at the norm of integrating considerations is that it does not address how to balance the three environmental, economic and social dimensions. The three considerations may each promote different if not opposite solutions. If, for instance, the stated objective is an improvement in the coastal environment, it may be that the negative pressures on that coastal environment are the result of an economically viable and socially important cornerstone industry. As a result, the coastal environment may be left to deteriorate, despite the awareness and integration of environmental considerations. In other words, the norm may be more useful in informing decisions and policies, and less useful in providing direction. 


\section{Concluding Remarks}

The article shows the existence of multiple concepts of integration relevant for ocean management, two of which are discussed and characterized as norms. The first norm calls for an IOM process to be developed or maintained. The second norm calls for environmental, social and economic considerations to be integrated into any policy, including an IOM policy. By analyzing these fundamentally different norms of integration, the article illustrates how existing integrated approaches to ocean management greatly differ.

The identification of these two internationally recognized norms would not have been possible if only formal legally binding sources had been consulted. Combining these sources with other internationally recognized sources has shown that the norm recommending an IOM process has worldwide support far beyond the 11 Mediterranean parties to the legally binding ICZM Protocol. ${ }^{89}$ Furthermore, relying on a broader set of sources, a broader scope of considerations should be integrated into ocean management and other policies. Thus, the article shows the value of investigating sources beyond the formal legally binding sources and of applying an adjustable normative lens.

Integrative concepts are compartmentalized by some experts as an environmental issue, ${ }^{90}$ much like sustainable development and the ecosystem approach. ${ }^{91}$ The norm requiring the integration of specific considerations which has occurred within the CBD regime has evolved from including only environmental concerns to embracing also economic and social considerations. The norm can be considered to have occurred in tandem with the development of the environmental law discourse promoting a broader set of objectives beyond mere environmental issues, to include economic and social development goals. ${ }^{92}$ The three considerations also mirror the three dimensions of the sustainable development principle. Good 
governance, suggested by some as the fourth dimension of sustainable development, even correlates in some respects with the suggestion to include clear and transparent premises when relying upon a holistic concept in a management instrument. ${ }^{93}$

A final comment on IOM policies, their scope and the objective of marine environmental protection is required. Although coastal states have some authority to respond to global negative pressures on the marine environment, such as those resulting from climate change and longrange transboundary pollution, this authority is largely insufficient to ensure the effectivity of any given State’s IOM regime. Indeed, a single nationally defined IOM process cannot provide the tools needed to reduce, prevent or prohibit some of the principal environmental challenges facing the marine environment, to which land-locked states also contribute. Therefore, the IOM policies of multiple states (or IOM in aggregation) will not lead to effective "ocean governance" at the international level. ${ }^{94}$ This shows the importance of establishing clear and transparent premises for IOM policies, not just out of national interest, but also for the benefit of the international community as a whole. For as Allott reminds us,

[t]he benefit of a power is the discretionary choices that it protects. The burden of a power is respect for the interests of society as a whole, which confers the power on the holder as the agent of all its members. ${ }^{95}$

Therefore, this article suggests that the scope of IOM should be clearly and transparently defined by each coastal state, including which integrative norms or concepts it uses, thereby clarifying how its ocean management is more or less integrated. 
(UNCED), United Nations Conference on Environment and Development. "Agenda 21 - Global Programme of Action on Sustainable Development." 1992.

Allott, Philip. "Power Sharing in the Law of the Sea." American journal of international law 77, no. 1 (1983): 1-30.

Assembly, United Nations General. "Rio Declaration on Environment and Development ", 1992.

Backer, Inge Lorange. "Integrasjonsprinsippet - Er Det Noe Bedre Alternativ?". In Pro Natura : Festskrift Til Hans Christian Bugge På 70Årsdagen 2. Mars 2012, edited by Ole Kristian Fauchald, Inge Lorange Backer, Christina Voigt, Hans Chr Bugge and Bård Sverre Tuseth, 42-55. Oslo: Universitetsforl., 2012.

Barnes, Richard. "The Law of the Sea Convention and the Integrated Regulation of the Oceans." International journal of marine and coastal law 27, no. 4 (2012): 859-66.

Brunne, Jutta. "Coping with Consent: Law-Making under Multilateral Environmental Agreements." Leiden Journal of International Law 15, no. 1 (2002): 1-52.

Brunnée, Jutta, and Stephen J. Toope. Legitimacy and Legality in International Law: An Interactional Account. Cambridge Studies in International and Comparative Law. Cambridge: Cambridge University Press, 2010. doi:DOI: 10.1017/CBO9780511781261.

Dupuy, Pierre-Marie. "Formation of Customary International Law and General Principles." Oxford University Press, 2008.

Giovannoni, E., and G. Fabietti. What Is Sustainability? A Review of the Concept and Its Applications. 2013. doi:10.1007/978-3-319-02168-3_2.

Jakobsen, Ingvild Ulrikke. "The Adequacy of the Law of the Sea and International Environmental Law to the Marine Arctic: Integrated Ocean Management and Shipping." Michigan State International Law Review 22, no. 1 (2013).

From a Functional to a Holistic Approach. Queen Mary Studies in International Law. Vol. 25, 2016. doi:10.1163/9789004324084_004.

Kidd, Sue. "Rising to the Integration Ambitions of Marine Spatial Planning: Reflections from the Irish Sea." Marine Policy 39 (2013): 273.

Kirk, Elizabeth A. "The Ecosystem Approach and the Search for an Objective and Content for the Concept of Holistic Ocean Governance." Ocean Development \& International Law 46, no. 1 (2015): 33-49.

Lévy, J. P. "The Need for Integrated National Ocean Policies." 9-12, 2009.

Lynch, Richard. Corporate Strategy. 2nd ed. ed. Harlow: Financial Times, 2000.

Morgera, Elisa, and Elsa Tsioumani. "Yesterday, Today, and Tomorrow: Looking Afresh at the Convention on Biological Diversity." Yearbook of International Environmental Law 21, no. 1 (2010): 3-40.

Rothwell, Donald R., and David L. VanderZwaag. Towards Principled Oceans Governanance. Routledge Advances in Maritime Research. Hoboken: Taylor and Francis, 2006.

Scott, Karen N. "Integrated Oceans Management: A New Frontier in Marine Environmental Protection." Chap. 21 In Oxford Handbook of the Law of the Sea, edited by Donald R. Rothwell, Alex G. Oude Elferink, Karen N. Scott and Tim Stephens, 463-90. Oxford: Oxford University Press, 2015.

Shelton, Dinah. Soft Law. 2009.

Tanaka, Yoshifumi. A Dual Approach to Ocean Governance : The Cases of Zonal and Integrated Management in International Law of the Sea. Ashgate International Law Series. Farnham: Ashgate, 2008.

Underdal, Arild. "Integrated" Marine Policy - What? Why? How? Studie (Fridtjof Nansen-Stiftelsen På Polhøgda). Vol. 191, Lysaker1979.

Westerlund, Staffan. "Miljörättsliga Mikroteser." Nordisk miljörättslig tidskrift/Nordic Environmental Law Journal 2017, no. 2 (2017).

Winby, Stuart, and Christopher G. Worley. "Management Processes for Agility, Speed, and Innovation." Organizational Dynamics 43, no. 3 (2014): 225-34. 
${ }^{1}$ For example, under the label of the "blue economy", a term which however has no generally accepted meaning. "For some, Blue Economy means the use of the sea and its resources for sustainable economic development. For others, it simply refers to any economic activity in the maritime sector, whether sustainable or not.” World Wildlife Fund (WWF), Report on the "Principles for a Sustainable Blue Economy”, available on the WWF website <d2ouvy59p0dg6k.cloudfront.net/downloads/15_1471_blue_economy_6_pages_final.pdf>.

${ }^{2}$ As evidenced by its inclusion as one of the themes of the G7 summit of 2018, <https://g7.gc.ca/en/g7-presidency/themes/working-together-climate-change-oceans-cleanenergy/>.

${ }^{3}$ The United Nations (UN) Oceans Conference to support the implementation of Sustainable Development Goal 14: to conserve and sustainably use the oceans, seas and marine resources for sustainable development. The need for an integrated approach was stressed in the resolution of the United Nation General Assembly (UNGA) A/RES/71/312, adopted on July 6, 2017. ${ }^{4}$ According to the analysis tool based on the national reporting system created by the Convention on Biological Diversity (CBD), adopted June 5, 1992, entered into force December 29, 1993, 1760 U.N.T.S. 79. According to the tool (Question 154), 33 countries have arrangements in place for the integrated management of marine and coastal ecosystems, 6 have no such arrangements (of which two are landlocked states), 47 consider themselves at the early stages of development of such (arrangements), and 19 consider themselves at an advanced stage of development. The analysis was conducted in August 2018, and the tool is available at $<$ www.cbd.int/reports/analyzer.shtml $>$.

${ }^{5}$ Protocol on Integrated Coastal Zone Management in the Mediterranean, to the Convention for the Protection of the Marine Environment and the Coastal Region of the Mediterranean, adopted 
at Barcelona on February 16, 1976, amended on June 10, 1995 and entered into force on March 24, 2011, 1858 U.N.T.S. 402.

${ }^{6}$ As expressed in a common statement by the Helsinki and OSPAR Commissions, created respectively under the Convention on the Protection of the Marine Environment of the Baltic Sea Area, 2099 U.N.T.S. 195, and the OSPAR Convention for the Protection of the Marine Environment of the North-East Atlantic, 2354 U.N.T.S 67. "First Joint Ministerial Meeting of The Helsinki and OSPAR Commissions (JMM) Bremen: 25 - 26 June 2003”, see $<$ http://www.helcom.fi/Documents/About\%20us/Convention\%20and\%20commitments/Ministeri al\%20declarations/First\%20Joint\%20Ministerial\%20Meeting\%20of\%20the\%20Helsinki\%20and \%20OSPAR\%20Commissions.pdf>.

${ }^{7}$ Ibid. Also promoted by the Arctic Council's Protection of the Arctic Marine Environment (PAME) Working Group which referred to an “integrated ecosystem-based management approach” in its 2004 Arctic Marine Strategic Plan, available at <pame.is/images/01_PAME/AMSP/AMSP_Nov_2004.pdf >.

${ }^{8}$ See for example: Ingvild Ulrikke Jakobsen, “Integrated Ocean Management in the Arctic: Comparative analyses of the implementation and use of MPAs in Canada and Norway", Ocean Yearbook 2018 (Brill 2018) p. 206; Ingvild Ulrikke Jakobsen, “The Adequacy of the Law of the Sea and International Environmental Law to the Marine Arctic: Integrated Ocean Management and Shipping”, Michigan State International Law Review (MSILR) 22, no. 1 (2013) p. 291; Yoshifumi Tanaka, A Dual Approach to Ocean Governance : The Cases of Zonal and Integrated Management in International Law of the Sea, Ashgate International Law Series (Routledge 2008) p. 1; Karen N. Scott, “Integrated Oceans Management: A New Frontier in Marine Environmental Protection”, Oxford Handbook of the Law of the Sea, ed. Donald R. Rothwell, et 
al. (Oxford University Press 2015) p. 463; Elizabeth A. Kirk, "The Ecosystem Approach and the Search for an Objective and Content for the Concept of Holistic Ocean Governance”, Ocean Development \& International Law 46, no. 1 (2015) p. 33; Donald R. Rothwell and David L. VanderZwaag, Towards Principled Oceans Governanance, Routledge Advances in Maritime Research (Routledge 2006) p. 19; Richard Barnes, "The Law of the Sea Convention and the Integrated Regulation of the Oceans”, International Journal of Marine and Coastal Law (IJMCL) 27, no. 4 (2012) p. 859.

${ }^{9}$ It is beyond the scope of this article to discuss all of the theories, aspects and dimensions of integration. For a general overview, see Sue Kidd, "Rising to the Integration Ambitions of Marine Spatial Planning: Reflections from the Irish Sea”, Marine Policy vol. 39 (2013) p. 274. Kidd discusses marine spatial planning, in relation to which she groups and quantifies a number of integration concepts. Underdal uses different criteria to discuss how marine policies can be integrated using the overarching criteria of comprehensiveness, aggregation, and consistency. See Arild Underdal, “Integrated Marine Policy - What? Why? How?”, Marine Policy vol. 4 issue 3 (1980) p. 159.

${ }^{10}$ In addition to the scholarly literature, two examples of integrative concepts from national IOM policies can be referred to including from the Canadian Ocean Stategy of 2002: “ Integrated Management is a commitment to planning and managing human activities in a comprehensive manner while considering all factors necessary for the conservation and sustainable use of marine resources and the shared use of ocean spaces" (available at $<$ http://www.dfompo.gc.ca/oceans/publications/cos-soc/index-eng.html>). The Norwegian plan for the "integrated management of the marine environment of the Norwegian Sea" explains "integrated ecosystem-based marine management” this way: "the term "integrated" is used to mean that the 
cumulative effects of all human activities on the marine environment are considered, and the term "ecosystem-based management” means that the management of human activities is based on the limits within which ecosystem structure, functioning, productivity and biological diversity can be maintained" (from the unofficial English translation of the 2009 Plan at p. 10, available at $<$ www.havforum.no $>$ ).

${ }^{11}$ As Staffan Westerlund urges, it is necessary to clarify the premises for and scope of investigation. See Staffan Westerlund, “Miljörättsliga Mikroteser”, Nordisk miljörättslig tidskrift/Nordic Environmental Law Journal 2017 no. 2 (2017) p. 7.

${ }^{12}$ As reflected in United Nations Convention of the Law of the Sea, adopted December 10, 1982 (UNCLOS), 1833 U.N.T.S. 3. Articles 2 and 56 define the sovereign and jurisdictional rights of the state; article 192 imposes upon states a general obligation to protect and preserve the marine environment; and article 193 recognizes the sovereign right of states to exploit their natural resources.

${ }^{13}$ The managing of the high seas is out of scope of this article.

${ }^{14}$ Barnes, IJMCL p. 863.

${ }^{15}$ Supra note 4.

${ }^{16}$ Philip Allott, "Power Sharing in the Law of the Sea”, American Journal of International Law 77 (AJIL) no. 1 (1983) p. 10.

${ }^{17}$ Supra note 12.

${ }^{18}$ UNCLOS, supra note 12, articles 2 and 17.

${ }^{19}$ UNCLOS, supra note 12, article 56 confers the enumerated rights (as well as jurisdiction in certain other specific matters) to coastal states, whereas article 58 confers certain rights upon other states. Moreover, the sovereign rights defined under article 56 confer other related powers 
upon coastal states, for example, the right to regulate bunkering of foreign fishing vessels in the EEZ, as confirmed by the International Law of the Sea Tribunal in M/V “Virginia G” (Panama/Guinea-Bissau), Judgment, ITLOS Reports 2014, p. 4 (para. 222).

${ }^{20}$ UNCLOS, article 77.

${ }^{21}$ Path dependence explains how the set of decisions one faces for any given circumstance is limited by the decisions one has made in the past or by the events that one has experienced, even though past circumstances may no longer be relevant. Definition from Dave Praeger, "Our Love Of Sewers: A Lesson in Path Dependence," Daily Kos (2008) p. 1.

${ }^{22}$ Similarly, the article takes the view that the sustainable development principle takes a holistic approach to, inter alia, development objectives.

${ }^{23}$ The Agenda 21 - Global Programme of Action on Sustainable Development was adopted in 1992 by the UN Conference on Environment and Development, alongside the Rio Declaration on Environment and Development, 31 I.L.M. p. 874. The title of chapter 17 to the Agenda 21 is "Protection of the oceans, all kinds of seas, including enclosed and semi-enclosed seas, and coastal areas and the protection, rational use and development of their living resources”. The Agenda 21 have since its adoption been reiterated in subsequent UN conferences and summits: for example, in 1997 in UNGA Resolution A/RES/S-19/2); in 2002 in the World Summit on Sustainable Development Conference Resolution A/CONF.199/L.1; in 2012 in the UN Conference on Sustainable Development Resolution A/C.2/66/L.59); and in 2015 in UNGA Resolution A/RES/70/1. The outcome of all these conferences and summits are available at

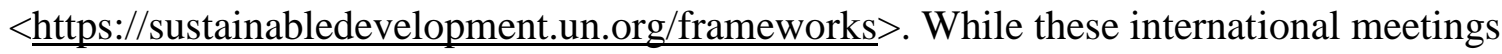
provided new formulations and developed the concept of sustainable development, they also reaffirmed previous iterations of the concept. 
${ }^{24}$ Chapter 17 of Agenda 21, ibid.

${ }^{25}$ Protocol on Integrated Coastal Zone Management in the Mediterranean, supra note 5. The Protocol is described on official EU webpages as an essential part of the EU Coastal and Marine Policy. See <ec.europa.eu/environment/marine/eu-coast-and-marine-policy/index_en.htm>. ${ }^{26}$ Ibid., article 2(f).

${ }^{27}$ A draft ICZM Protocol to the Nairobi Convention of the Western Indian Ocean exists, subject to final negotiation by the Convention parties as part of its 2018-2022 work program, according to UNEP/EAF/CP.9/2/Rev.1. The draft, dating from March 2016, includes alternative definitions, all referring to ICZM as a dynamic process of governance or management, with some of the definitions also referring to sustainability. The draft is available at <wedocs.unep.org/bitstream/handle/20.500.11822/11178/UNEP(DEPI)-EAF-NEG.3-ICZMINF-DOC\%207\%20Text\%20of\%20Second\%20Negotiated\%20Draft\%20of\%20\%20ICZM\%20Protocol\%20.pdf ?sequence $=1 \&$ isAllowed $=\mathrm{y}>$.

${ }^{28} \mathrm{COP}$ decision in annex 1 adopting IMCAM as the first Programme Element in the CBD Programme of Work on marine and coastal biodiversity, UNEP/CBD/COP/DEC/VII/5, and COP decision on enhancing the implementation of integrated marine and coastal area management, $\mathrm{UNEP} / \mathrm{CBD} / \mathrm{COP} / \mathrm{DEC} / \mathrm{VIII} / 22$.

${ }^{29}$ Including the Action Plan for the Sustainable Ocean Initiative (2015-2020), available at <www.cbd.int/doc/meetings/mar/soiom-2014-02/official/soiom-2014-02-actionplan-en.pdf>.

${ }^{30}$ Secretariat of the Convention on Biological Diversity, CBD Technical Series No. 14 on “Integrated Marine and Coastal Area Management (IMCAM) Approaches for Implementing the Convention on Biological Diversity” (2004) and CBD Technical Series No. 76 on "Integrated 
Coastal Management for the Achievement of the Aichi Biodiversity Targets: Practical Guidance for Implementation Based on Experience and Lessons Learned from Coastal and Ocean Governance in the Seas of East Asia” (2015), both available at <www.cbd.int/doc/meetings/mar/imcam-01/other/imcam-01-cbd-ts-14-en.pdf>.

${ }^{31}$ For example, in the titles of the documents cited in the preceding note.

${ }^{32} \mathrm{COP}$ decision on enhancing the implementation of integrated marine and coastal area management, supra note 28, paragraph 3(c).

${ }^{33}$ For example, in ibid, inviting CBD parties and other governments to develop and adopt, where appropriate a national integrated marine and coastal area strategy.

${ }^{34}$ CBD Technical Series No. 14, supra note 30.

${ }^{35}$ Strategy document of the Ad Hoc Technical Expert Group on the Implementation of Integrated Marine and Coastal Area Management, UNEP/CBD/IMCAM/1/2, available at <www.cbd.int/doc/meetings/mar/imcam-01/official/imcam-01-02-en.pdf > .

${ }^{36}$ Supra note 28.

${ }^{37}$ Notes 58 and 63.

${ }^{38}$ CBD Technical Series No. 14, supra note 30, at p. 19.

${ }^{39}$ More implicitly stated in the decisions, for example, UNEP/CBD/COP/DEC/VII/5 operational goal 1.2, and COP VIII/22 3 (f), yet clearly included in the objectives of the CBD Convention in article 1 . These documents refer to biodiversity, rather than the environment, but for the sake of simplicity, the term environment is used throughout this article.

${ }^{40}$ Recommendation by the CBD Subsidiary body on scientific, technical and technological advice, UNEP/CBD/SBSTTA/REC/XIV/3, paragraph 14. Available at 
$<$ www.cbd.int/convention/results/?id=12250\&kw=integrated\%20marine\&t0=integrated\%20mari ne>.

${ }^{41}$ Document by the Ad Hoc Technical Expert Group on the Implementation of Integrated Marine and Coastal Area Management (IMCAM), explaining the relationship between the CBD targets and relevant targets adopted by other processes, UNEP/CBD/IMCAM/1/ INF/2, available at

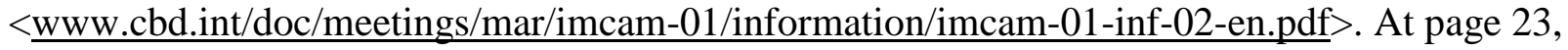
the Expert Group states: “More specifically, the World Summit on Sustainable Development in its plan of implementation lists a number of related actions, which include proper coastal land use, watershed planning, and integration of integrated marine and coastal area management into key sectors. In this context, there is a need for effective strategies for waste reduction and management in order to reduce land-based pollution and offshore dumping, and a need for adequate port reception facilities for wastes from ships.”

${ }^{42}$ CBD Technical Series No. 76, supra note 30, at p. 15.

${ }^{43}$ As established by the 2006 Haikou Partnership Agreement. For information about PEMSEA, see $<$ www.pemsea.org $>$.

${ }^{44}$ ICM Code and ICM Framework as described by PEMSEA, at <www.pemsea.org/ourwork/integrated-coastal-management/ICM-code>.

${ }^{45}$ As explained by PEMSEA in the introduction to the ICM code, ibid.

${ }^{46}$ ICM Code, section 3.0., ibid.

${ }^{47}$ Ibid., as evident even from the Code's table of contents.

${ }^{48}$ CBD Technical Series no. 76 states on p. 15 that the concepts of IMCAM, ICM and ICZM are largely similar. 
${ }^{49}$ In contrast to, for example, more extensive integration by institutional integration or common leadership.

${ }^{50}$ Article 5 of the ICZM Protocol, on objectives, refers to preservation and sustainable use, whereas the Protocol in multiple other provisions refers to protection (for example in article 8), as does the Convention to which the protocol is annexed. Supra note 5.

${ }^{51}$ See, for example, Agenda 12 chapter 17.1 (IMCM), supra note 23 and ICM Code section 1.0 p.3 (ICM), supra note 44.

${ }^{52}$ Supra note 39.

${ }^{53}$ UNCLOS, article 192. According to the Award in the Matter of the South China Sea: "The corpus of international law relating to the environment, which informs the content of the general obligation in Article 192, requires that states ensure that activities within their jurisdiction and control respect the environment of other states or of areas beyond national control.” Arbitration of the Matter of the South China Sea, between the Republic of Philippines and The People's Republic of China, 12 July 2016, p. 373. Available at $<$ https://pcacases.com/web/sendAttach/2086 $>$. The Tribunal refers in the quote to the Advisory Opinion of the International Court of Justice on the Legality of the Threat of Use of Nuclear Weapons, ICJ Reports 1996, p. 226.

${ }^{54}$ For example, the first CBD COP decisions to mention the ecosystem approach was in 1995 (UNEP/CBD/COP/2/19, decision II/8) and the Malawi principles on the ecosystem approach were developed in 1998. Although the CBD defines and refers to ecosystems, in articles 2, 8 and 9, it does not refer to the ecosystem approach. 
${ }^{55}$ Some institutions and scholars use the terms integrated ocean management and ecosystem approach to management interchangeably, including the Arctic Council, supra note 7 and Jakobsen, MSILR p. 298, supra note 8.

${ }^{56}$ See section III 1 of this article for further details and references.

${ }^{57}$ For details on the processes, see the definitions and descriptions of each of the four concepts in the sources referred to in section III.1, from footnote 23 to 47 . For similar, but more extensive representations of management processes for marine spatial planning, see Vanessa Stelzenmüller et al., "Monitoring and evaluation of spatially managed areas: A generic framework for implementation of ecosystem based marine management and its application”, Marine Policy vol. 37 (2013) p. 149. See also the Monitoring and Evaluation of Spatially Manage Areas (MESMA) project, which addresses management processes relevant for marine spatial planning including an evaluation framework: <www.mesmacentralexchange.eu/analyses.html>.

${ }^{58}$ For a simplified, but essentially similar explanation of the management process for organizations, see Stuart Winby and Christopher G. Worley, "Management Processes for Agility, Speed, and Innovation”, Organizational Dynamics 43 no. 3 (2014) p. 227. For corporate management processes, see for instance Richard Lynch, Corporate Strategy, 2nd ed. (Pearson Education 2000) p. 26.

${ }^{59}$ In terms of the conventional approach, according to which legal norms have to originate in one of the sources listed in article 38 of the Statute of the International Court of Justice, including most prominently treaties and customary law. The interactional approach uses different criteria of legality. See Jutta Brunnée and Stephen J. Toope, “Legitimacy and Legality in International Law: An Interactional Account”, Cambridge Studies in International and Comparative Law no. 67 (Cambridge University Press 2010) p. 6. 
${ }^{60}$ Pierre-Marie Dupuy, "Formation of Customary International Law and General Principles”, The Oxford Handbook of International Environmental Law (Oxford University Press 2008), p. 457 : "It, nevertheless, should be accepted by scholars that the practice of citing as many treaties as possible that contain references, in analogous terms, to the same type of conduct is simply insufficient to convincingly demonstrate that a rule recognized in treaty law has also become binding in the field of custom. As a matter of fact, even the fulfillment of the criteria laid down by the court in 1969 is not enough to ensure that a rule has passed from a treaty into general international law. Other contextual and sociological conditions (including political ones) must be met - the balance and combination of which can hardly be given definitive formulation.” 61 "What distinguishes law from other types of social ordering is not form, but adherence to specific criteria of legality: generality, promulgation, non-retroactivity, clarity, noncontradiction, not asking the impossible, constancy, and congruence between rules and official action.” See Brunnée and Toope, supra note 59, at p. 6, referring to Lon Luvois Fuller, "The Morality of Law”, Storrs Lectures on Jurisprudence (Yale University Press 1969). The normative characteristics of this article are clearly inspired by the Brunnée and Toope criteria. However, in contrast to their approach and as can be readily seen in contrast to the above citation, this article does not rely upon criteria that address the content of a norm, but rather upon those that concern its influence.

${ }^{62}$ These characteristics resonate partly with the characteristics underpinning binding norms. Otherwise, arguably, they bolster authority both individually and in combination. ${ }^{63}$ The numbers are drawn from the websites of the institutions established in connection with the agreements: <sustainabledevelopment.un.org/outcomedocuments/agenda21> and $<$ www.cbd.int/information/parties.shtml $>$. The self-proclaimed global leader on integrated 
management of the ocean is the United States of America. For information on the United States general approach to IOM, see <oceanservice.noaa.gov/GLIMO/welcome.html>. ${ }^{64}$ See $<$ http://pemsea.org/about-pemsea/our-partners/country-partners $>$. ${ }^{65}$ See $<$ http://www.paprac.org/iczm-protocol $>$. ${ }^{66}$ National reporting to the CBD shows that only 6 of the 132 reporting states, of which two are coastal states and two are island states, have not yet made any arrangements to implement integrated ocean management. The six states are Bahamas, Bosnia-Hercegovina, Congo, Djibouti, Latvia, and Trinidad and Tobago.

${ }^{67}$ The normative characteristics are inspired by some of the criteria of legality proposed by the interactional approach. See Brunnée and Toope, supra note 61.

${ }^{68}$ According to Shelton, “[n]onbinding norms or informal social norms can be effective and offer a flexible and efficient way to order responses to common problems. They are not law and they do not need to be in order to influence conduct in the desired manner." Dinah Shelton, "Soft Law”, Routledge Handbook of International Law (Routledge 2009) p. 79.

${ }^{69}$ More precisely, the norm requires some states (ICZM parties) and recommend other states to abide by it.

${ }^{70}$ The United Nations Conference on Environment and Development (UNCED) held in Rio de Janeiro, Brazil, June 3-14, 1992.

${ }^{71}$ Supra note 23.

${ }^{72}$ Award in the Arbitration regarding the Iron Rhine (“Ijzeren Rijn”) Railway between the Kingdom of Belgium and the Kingdom of the Netherlands, PCA, 2005 stating in para 59: “Today, both international and EC law require the integration of appropriate environmental measures in the design and implementation of economic development activities. Principle 4 of 
the Rio Declaration on Environment and Development, adopted in 1992, 31 I.L.M. p. 874, at p. 877, which reflects this trend, provides that "environmental protection shall constitute an integral part of the development process and cannot be considered in isolation from it”. Importantly, these emerging principles now integrate environmental protection into the development process. Environmental law and the law on development stand not as alternatives but as mutually reinforcing, integral concepts (...)”. The International Court of Justice in the GabčíkovoNagymaros case stated that "[t]his need to reconcile economic development with protection of the environment is aptly expressed in the concept of sustainable development". GabčíkovoNagymaros (Hungary/Slovakia), Judgment, I.C.J. Reports 1997, p. 7 at p. 78, para. 140.

${ }^{73}$ Agenda 21, chapter 8, section 8.3 a), supra note 23.

${ }^{74}$ Ibid., section 8.4(a).

${ }^{75}$ Principle 4 of the Rio Declaration, supra note 23.

${ }^{76}$ Resolution by the UNGA, A/RES/66/288, available at $<$ www.un.org/ga/search/view_doc.asp?symbol=A/RES/66/288\&Lang=E $>$.

${ }^{77}$ Although there are necessarily nuances, for the purposes of this discussion the focus is on the larger picture.

${ }^{78} \mathrm{CBD}$ article 1.

${ }^{79} \mathrm{UNEP} / \mathrm{CBD} / \mathrm{COP} / \mathrm{DEC} / \mathrm{VII} / 11$ Annex 1, paragraph 3. Another example is $\mathrm{UNEP} / \mathrm{CBD} / \mathrm{COP} / 3 / 38$ decision III/9 on the Implementation of Articles 6 and 8 of the convention, which use the word "include" instead of "integrate" and urges parties to "include in their national plans or strategies and legislation measures for: (a) The conservation of biological diversity both in situ and ex situ; (b) The integration of biological diversity objectives in relevant sectoral policies in order to achieve conservation and sustainable use of biological diversity; and 
(c) The equitable sharing of benefits arising out of the use of genetic resources.” Paragraphs (a), (b) and (c) correlate to the environmental, economic and social considerations discussed in this article.

\section{${ }^{80} \mathrm{UNEP} / \mathrm{CBD} / \mathrm{COP} / \mathrm{DEC} / \mathrm{IX} / 8$.}

${ }^{81}$ See for example CBD COP decision, UNEP/CBD/COP/DEC/X/2, which provides: "National biodiversity strategies and action plans are key instruments for translating the Strategic Plan to national circumstances, including through the national targets, and for integrating biodiversity across all sectors of government and society.”.

${ }^{82}$ With regard to the CBD, Morgera and Tsioumani declare that the "CBD COP's normative activity is testimony to an intense, evolving, and creative interpretation of the convention by the international community.” Elisa Morgera and Elsa Tsioumani, "Yesterday, Today, and Tomorrow: Looking Afresh at the Convention on Biological Diversity”, Yearbook of International Environmental Law 21 no. 1 (Oxford Academic 2010) p. 4 (footnote omitted). ${ }^{83}$ See supra note 23 for references to multiple SD Documents. Additionally, the UNGA in 2015 adopted a plan of action, “Transforming Our World: The 2030 Agenda for Sustainable Development” (A/70/L.1). The Agenda 2030 supports previous iterations of the sustainable development principle, but also reformulates and develops "sustainable development" in its own way. Agenda 2030 is structured around 17 so-called sustainable development goals and for this reason, this article considers it a goal-oriented document.

${ }^{84}$ Supra note 60.

${ }^{85}$ Among these sources, the Rio Declaration and Agenda 21, supra note 23, adopted by more than 178 governments are key sources of the sustainable development principle together with the CBD which has 197 State parties, supra note 63. 
${ }^{86}$ Supra note 59.

87 This conclusion appears to be implicitly supported by Morgera and Tsioumani, supra note 82, at p. 25, who state that CBD strategies and goals urge parties to "integrate biodiversity values not only into national (..) planning (as already mandated by CBD Article 6) but also (...) taking into account national socio-economic conditions”. Author’s emphasis.

${ }^{88}$ Inge Lorange Backer, “Integrasjonsprinsippet - Er Det Noe Bedre Alternativ?”, Pro Natura: Festskrift Til Hans Christian Bugge På 70-Årsdagen 2. Mars 2012, Ole Kristian Fauchald et al. (eds.) (Universitetsforlaget 2012) p. 42. Elise Johansen, “Norway’s Integrated Ocean Management: A need for stronger protection of the environment”, Ocean Yearbook 2018 (Brill 2018) p. 239.

${ }^{89}$ Supra note 63.

${ }^{90}$ Ingvild Ulrikke Jakobsen, “From a Functional to a Holistic Approach”, Queen Mary Studies in International Law vol. 25 (2016) p. 66 and Jakobsen, MSILR p. 298, supra note 8.

${ }^{91}$ With regard to sustainable development, see Elena Giovannoni and Giacomo Fabietti, "What Is Sustainability? A Review of the Concept and Its Applications”, Integrated Reporting, Cristiano Busco et al. (eds.) (Springer Verlag 2013) p. 24. The ecosystem approach is discussed in the context of international environmental law by Froukje Maria Platjouw, "Environmental Law and the Ecosystem Approach: The Need for Consistency and Coherence in Environmental Law of the Maintenance of Ecosystem Integrity”, Series of dissertations submitted to the Faculty of Law, University of Oslo No. 80 (2015) and Vito De Lucia, “The Ecosystem Approach in International Environmental Law: A Biopolitical Critique”, Dissertation submitted to the Faculty of Law, UIT The Arctic University of Tromsø (2015). 
${ }^{92}$ Giovannoni and Fabietti, ibid on p. 6, explain: "The literature reviewed in the previous section, as well as the three evolving (environmental, social and business) discourses make it possible to identify and conceptualise the key dimensions of the concept of sustainability, as well as to emphasise the need for an integrated approach among the three dimensions. This need has also been acknowledged by Drexhage and Murphy (2010): we need to take 'sustainable development out of the environment 'box' and considering wider social, economic, and geopolitical agendas' (p. 20). In other words 'sustainable development embodies integration, and understanding and acting on the complex interconnections that exist between the environment, economy, and society’.”. The authors cite John Drexhage and Debora Murphy, “Sustainable development: From Brundtland to Rio 2012”, Background paper for the high level panel on global sustainability (2010) p. 20, available at $<$ http://www.surdurulebilirkalkinma.gov.tr/wpcontent/uploads/2016/06/Background_on_Sustainable_Development.pdf>

${ }^{93}$ Giovannoni and Fabietti, ibid, at p. 28.

${ }^{94}$ This conclusion has been put forward by some experts, including Jean-Pierre Lévy, “The Need for Integrated National Ocean Policies”, Environmental Policy and Law Vol.39 (1) (2009) p. 9.

${ }^{95}$ Allott, AJIL, supra note 16, at p. 10. 